\title{
Solitary bone cyst of the mandible: a case report and brief review of literature
}

\author{
GunaShekhar Madiraju, ${ }^{1}$ SuryanarayanaRaju Yallamraju, ${ }^{1}$ Vijayakumar Rajendran, ${ }^{2}$ \\ Kolasani SrinivasaRao ${ }^{3}$
}

\begin{abstract}
${ }^{1}$ Bangalore, Karnataka, India ${ }^{2}$ Chennai, Tamil Nadu, India ${ }^{3}$ Governemnt Dental College, Vijayawada, Andhra Pradesh, India
\end{abstract}

Correspondence to Dr GunaShekhar Madiraju, drgsm2011@gmail.com

Accepted 10 July 2014

\section{SUMMARY}

A solitary bone cyst is a non-neoplastic osseous lesion comprising $1 \%$ of all the cysts affecting the jaws. They are generally asymptomatic, usually detected incidentally during routine radiological assessment and are less common in the mandibular anterior region. This article presents a well-documented case involving a solitary bone cyst affecting the mandibular symphysis in a 12year-old boy with no history of previous trauma. Simple curettage of the bone cavity resulted in the resolution of the lesion with progressive osseous regeneration. No evidence of recurrence was noted 2 years after the treatment.

\section{BACKGROUND}

A solitary bone cyst (SBC) is a non-neoplastic osseous lesion comprising $1 \%$ of all the cysts affecting the jaws. ${ }^{12}$ While the term 'traumatic bone cyst' is more widely used in the literature, the international histological classification adopted by the WHO for odontogenic tumours uses the term 'solitary bone cyst'. 3 SBCs commonly affect the mandibular body between the canine and the third molar. Mandibular symphysis is less commonly affected. ${ }^{4} 5$ They are more frequently seen during the second decade of life and sex distribution is quite even. ${ }^{5}{ }^{6}$ Lesions are generally asymptomatic, however, a few authors have reported symptoms including pain, tooth sensitivity, paraesthesia and delayed displacement of the inferior dental canal. ${ }^{67}$ Surgical intervention is the most widely chosen treatment option although spontaneous resolution of lesions has been reported. This article presents a case of SBC involving the anterior mandible managed by surgical curettage in a 12 -year-old boy.

\section{CASE PRESENTATION}

A 12-year-old boy was referred to the paediatric dental setting by a general dentist for evaluation of a radiolucent lesion in the anterior mandible discovered during routine radiographic examination. He was in his early permanent dentition stage and presented normal oral structures. Silver amalgam restorations were seen on the occlusal surfaces of the first permanent molars in all the four quadrants.

Panoramic radiograph revealed a wellcircumscribed, unilocular, radiolucent area located in the mandibular symphysis giving a typical scalloped appearance between the roots of the involved teeth, that is, 33-43 (Federation Dentaire Internationale), measuring approximately $2.0 \times 2.0 \mathrm{~cm}$ in diameter (figure 1). The lesion was asymptomatic and no cervical lymphadenopathy was detected. On intraoral examination, the overlaying mucosa in the mandibular anterior region appeared normal. On palpation, no expansion of cortical bone, either buccally or lingually, was evident (figure 2).

Mandibular incisors and canines showed no mobility and had responded positively to electric and thermal pulp vitality tests. The boy's medical history was unremarkable and there was no history of trauma to the jaws. Routine biochemical and haematological tests were within normal limits. Differential diagnosis included central giant cell granuloma of traumatic or endocrinological aetiology, aneurysmal bone cyst and haemangioma. Aspiration of the cystic lesion yielded no pus or haemorrhages other than scanty serosanguineous fluid which ruled out the possibility of a vascular tumour. A tentative diagnosis of SBS was made and surgical exploration of the lesion was planned.

\section{TREATMENT}

Under local anaesthesia, an incision was made in the labial vestibule and a mucoperiosteal flap was raised exposing the buccal cortical bone which appeared fragile and thinned out. No evidence of bony expansion was noticed. A window was made with a surgical bur to gain access to the lesion. The bony cavity was empty, devoid of epithelial lining and scanty straw-coloured fluid was noticed. Surgical curettage of the cavity walls was performed excluding the roof, to preserve the vitality of adjacent teeth. Subsequently, the surgical site was closed and sutured. The resulting available material for histopathological examination was very scant and did not permit a definitive microscopic examination. These findings were highly suggestive for the diagnosis of SBC.

\section{OUTCOME AND FOLLOW-UP}

In the immediate postoperative course, antibiotic coverage was provided (amoxicillin $500 \mathrm{mg}$, twice daily, 7 days) along with analgaesic and antiinflammatory medication (ibuprofen $300 \mathrm{mg}$, three times a day, 5 days). Local cold application and home oral care instructions were advised. Postoperative healing was uneventful. A follow-up panoramic radiograph taken after 6 months duration revealed resolution of the lesion with complete bone formation (figure 3). Mandibular anterior teeth had remained responsive to pulp vitality tests at this follow-up appointment. Further panoramic radiograph taken 24 months after the 


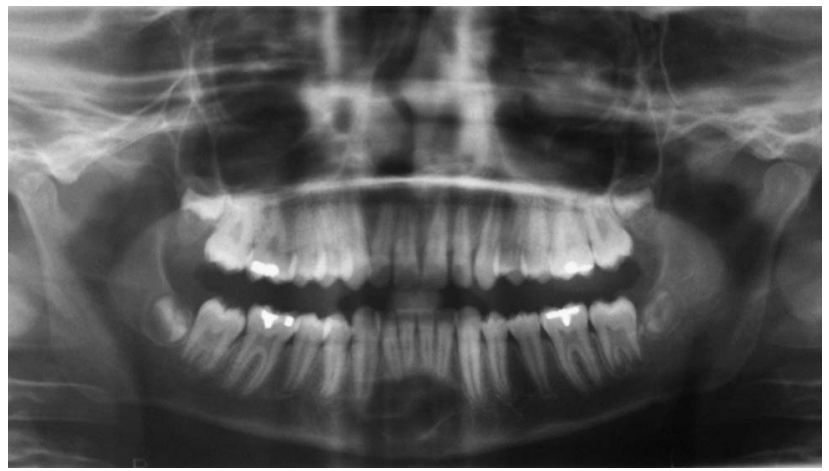

Figure 1 Initial pantomograph showing evidence of lesion with a typical scalloped appearance in the mandibular symphysis region.

treatment revealed no abnormal findings at the site of lesion (figure 4).

\section{DISCUSSION}

The aetiopathogenesis of SBC is not yet clearly understood. Several theories have been proposed in the literature including cystic degeneration of fibro-osseous lesions, intraosseous vascular anomalies, alteration of bony metabolism and low level of infection. The most widely accepted explanation suggests that liquefactive necrosis or resorption of blood clot following intramedullar haemorrhage due to trauma results in the destruction of the surrounding bone by enzymatic activity, thereby causing enlargement of the bone cavity. ${ }^{8}$ However, extreme variations regarding the presence of a history of trauma in most reported cases may be a limitation to this theory. Our patient had reported no history of trauma and so the principal aetiological factor could not be established in this case.

SBC is predominantly seen in the mandible, more frequently involving the posterior region ${ }^{9}$ and less common in the anterior mandible. ${ }^{5}{ }^{10}$ It is usually detected incidentally during routine radiographic examination, which can be attributed to the asymptomatic nature of the lesion. Radiographically, SBC usually appears as an unilocular radiolucent area with an irregular, well-defined or partly well-defined outline and with or without a sclerotic lining around the periphery of the lesion. Projection of the lesion into the inter-radicular bone spaces produces a scalloping effect around the roots of the associated teeth. ${ }^{11}$ Root resorption is rather uncommon and the surrounding teeth are vital. ${ }^{12}$

The bone cavity may either be empty or present a thin connective tissue layer with a scant liquid content. Howe ${ }^{13}$

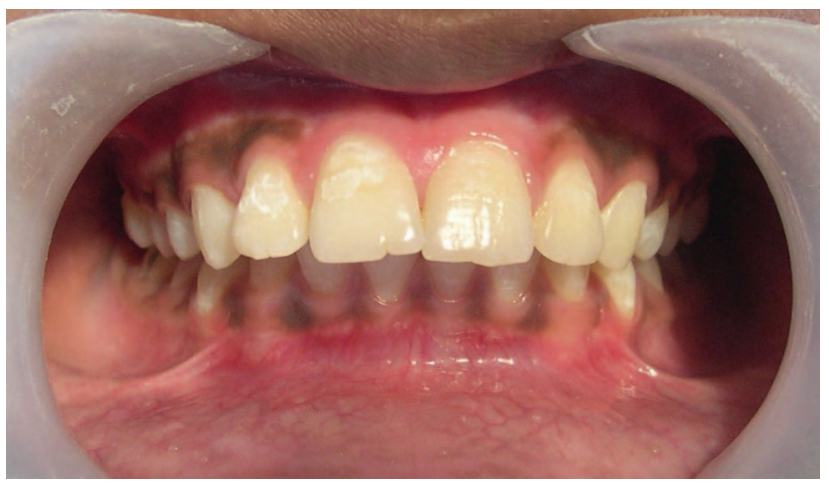

Figure 2 Intraoral picture of the lower anterior region.

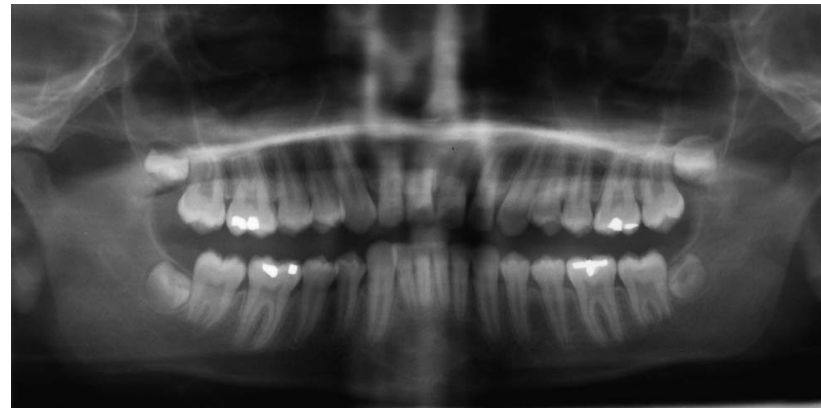

Figure 3 Pantomograph showing resolution of the lesion with the bone formation 6 months after treatment.

supported the theory which stated that the content of the cavity depends on the length of the time that the cyst has existed. In the early stages, the lesion usually contains blood or serosanguineous fluid that diminishes with the age of the lesion and eventually becomes empty. Since material for histological examination may be scant or non-existent, it is very often difficult for a definite histological diagnosis to be achieved. ${ }^{7}$ Indeed, the diagnosis of SBC can be established only after surgical exploration of the bone cavity. In the present case, negative aspiration of the cystic lesion other than scanty serosanguineous fluid, and the absence of bony expansion and pain, ruled out the possibility of a vascular tumour and aneurysmal bone cyst, respectively.

The case described here presented clinical data that was in agreement with the previous literature. The patient was in the second decade of life; the lesion was asymptomatic and was discovered incidentally during routine radiographic examination. Further, the radiological, histopathological and operative findings of the case corroborate the literature. Surgical exploration followed by curettage of the bony walls has been the most widely recommended treatment for SBC. ${ }^{5}{ }^{12}$ It serves as a diagnostic manoeuvre and as definitive treatment by producing bleeding in the cavity followed by clot formation, which eventually is replaced by bone. ${ }^{10}$ While spontaneous resolution has been reported to occur in some bone cysts, ${ }^{14}$ failure or delay in providing treatment may predispose to a possible pathological mandibular fracture. ${ }^{15}$

Resolution usually takes about 6 months or longer, depending on the size of the lesion. ${ }^{16}$ The prognosis is usually good and recurrence is rare. Precious and $\mathrm{McFadden}{ }^{17}$ had reported a case of traumatic bone cyst that had failed to respond to surgical curettage. On recurrence, a marked increase in the size with multilocular appearance was noted on the radiograph. Osseous

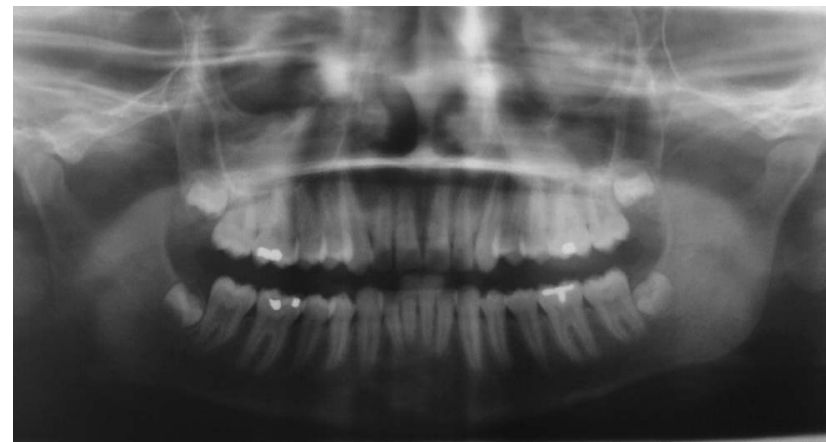

Figure 4 Follow-up pantomograph taken 24 months after treatment. 
regeneration and resolution of the lesion was achieved by the injection of autogeneic blood into the bony cavity. ${ }^{17}$

Other alternative treatments involving the use of allogenic materials like lyophilised bone, hydroxyapatite or gel foam have been suggested to fill the bone cavity in cases where conventional management fails and osteo-integrated implant rehabilitation is required. ${ }^{10} 16{ }^{18}$ Simple curettage of the walls of the bone cavity, in our case, produced favourable results characterised by progressive osseous regeneration within 6 months duration with no evidence of recurrence 2 years after the treatment.

\section{Learning points}

- A solitary bone cyst is a non-neoplastic osseous lesion usually detected incidentally during routine radiological examination due to its asymptomatic nature.

- Absence of epithelial lining is a characteristic feature of this lesion. Radiologically, it produces a scalloping effect around the roots of associated teeth.

- Surgical curettage of the bone cavity walls is indicated as it aids in confirming the diagnosis and may by itself be curative.

Acknowledgements The authors acknowledge the oral surgery unit for their valuable guidance and support.

Contributors All authors have made substantial contributions to the manuscript and all have reviewed the final paper prior to its submission. GSM was the guarantor.

Competing interests None.

Patient consent Obtained.
Provenance and peer review Not commissioned; externally peer reviewed.

\section{REFERENCES}

1 Harnet JC, Lombardi T, Klewansky P, et al. Solitary bone cyst of the jaws: a review of the etiopathogenic hypotheses. J Oral Maxillfac Surg 2008;66:2345-8.

2 Shear M. Cysts of the oral regions. 3rd edn. Oxford: Wright PSG, 1992.

3 Kramer IR, Pindborg JJ, Shear M. The WHO histological typing of odontogenic tumours. A commentary on the Second Edition. Cancer 1992;70:2988-94.

4 Xanthinaki AA, Choupis KI, Tosios K, et al. Traumatic bone cyst of the mandible of possible iatrogenic origin: a case report and brief review of the literature. Head Face Med 2006;2:40.

5 Discacciati ED, de Faria VM, Garcia NG, et al. Idiopathic bone cavity: case series involving children and adolescents. J Investig Clin Dent 2012;3:103-8.

6 Hansen L, Sapone J, Sproat R. Traumatic bone cysts of jaws. Report of sixty-six cases. Oral Surg 1974;37:899-910.

7 MacDonald-Jankowski DS. Traumatic bone cysts in the jaws of a Hong Kong Chinese population. Clin Radiol 1995;50:787-91.

8 Baqain $\mathrm{ZH}$, Jayakrishnan A, Farthing PM, et al. Recurrence of a solitary bone cyst of the mandible: case report. Br J Oral Maxillofac Surg 2005;43:333-5.

9 Martins-Filho PR, Santos Tde S, Araujo VL, et al. Traumatic bone cyst of the mandible: a review of 26 cases. Braz J Otorhinolaryngol 2012;78:16-21.

10 Penarrocha-Diago M, Sanchis-Bielsa JM, Bonet-Marco J, et al. Surgical treatment and follow-up of solitary bone cyst of the mandible: a report of seven cases. $\mathrm{Br} J$ Oral Maxillofac Surg 2001;39:221-3.

11 Ferreira $0 \mathrm{Jr}$, Damante JH, Lauris JRP. Simple bone cyst versus odontogenic keratocyst: differential diagnosis by digitized panoramic radiographs. Dentomaxillofac Radiol 2004;33:373-8.

12 Nelson BL. Solitary bone cyst. Head Neck Pathol 2010;4:208-9.

13 Howe GL. Haemorrhagic cysts of the mandible. Br J Oral Surg 1965;3:77-91.

14 Damante JH, Da S Guerra EN, Ferreira $0 \mathrm{Jr}$. Spontaneous resolution of simple bone cysts. Dentomaxillofac Radiol 2002;31:182-6.

15 Hughes CL. Hemorrhagic bone cyst and pathologic fracture of mandible: report of case. Oral Surg 1969;27:345-6.

16 Cortell-Ballester I, Figueiredo R, Berini-Aytés L, et al. Traumatic bone cyst: a retrospective study of 21 cases. Med Oral Patol Oral Cir Bucal 2009;14:E239-43.

17 Precious DS, McFadden LR. Treatment of traumatic bone cyst of mandible by injection of autogeneic blood. Oral Surg Oral Med Oral Pathol 1984;58:137-40.

18 Dellinger TM, Holder R, Livingston HM, et al. Alternative treatments for a traumatic bone cyst: a longitudinal case report. Quintessence Int 1998;29:497-502.

Copyright 2014 BMJ Publishing Group. All rights reserved. For permission to reuse any of this content visit

http://group.bmj.com/group/rights-licensing/permissions.

BMJ Case Report Fellows may re-use this article for personal use and teaching without any further permission.

Become a Fellow of BMJ Case Reports today and you can:

- Submit as many cases as you like

- Enjoy fast sympathetic peer review and rapid publication of accepted articles

- Access all the published articles

- Re-use any of the published material for personal use and teaching without further permission

For information on Institutional Fellowships contact consortiasales@bmjgroup.com

Visit casereports.bmj.com for more articles like this and to become a Fellow 